\title{
Influence of the Thermal Energy Storage Strategy on the Performance of a Booster Heat Pump for Domestic Hot Water Production System Based on the Use of Low Temperature Heat Source
}

\author{
Ximo Masip, Emilio Navarro-Peris *(1) and José M. Corberán \\ Instituto Universitario de Investigación en Ingeniería Energética (IUIIE), Universitat Politècnica de València, \\ 46022 València, Spain; xmasip@iie.upv.es (X.M.); corberan@ter.upv.es (J.M.C.) \\ * Correspondence: emilio.navarro@iie.upv.es
}

Received: 12 November 2020; Accepted: 9 December 2020; Published: 14 December 2020

\begin{abstract}
Energy recovery from a low temperature heat source using heat pump technology is becoming a popular application. The domestic hot water demand has the characteristic of being very irregular along the day, with periods in which the demand is very intensive and long periods in which it is quite small. In order to use heat pumps for this kind of applications efficiently, the proper sizing and design of the water storage tank is critical. In this work, the optimal sizing of the two possible tank alternatives, closed stratified tank and variable-water-volume tank, is presented, and their respective performance compared, for domestic hot water production based on low temperature energy recovery in two potential applications (grey water and ultra-low temperature district heating). The results show that the efficiency of these kind of systems is very high and that variable-water-volume tanks allow a better use of the energy source, with an $8 \%$ higher exergy efficiency and around $3 \%$ better seasonal performance factor (SPF), being able to provide similar comfort levels with a smaller system size.
\end{abstract}

Keywords: domestic hot water DHW; heat pump; thermal energy storage TES; waste heat; exergy analysis; ultra low temperature district heating; energy efficiency; size optimization

\section{Introduction}

A problem that is often debated nowadays is that of the increase of the total primary energy consumption worldwide. It has several associated critical global problems like climate change or the sustainability of it derived from a limited amount of resources. Its solution without affecting the people level of comfort will be one of the biggest challenges for the next years. The European Union (EU) intends to address this problem with a long-term strategy promoting the use of renewable sources of energy and increasing the efficiency of the systems in order to decrease the $\mathrm{CO}_{2}$ emissions to the 80-95\% level regarding the levels of 1990 [1]. According to the EU, the residential sector, which actually accounts for the $40 \%$ energy consumption and $36 \%$ of the $\mathrm{CO}_{2}$ emissions in Europe [2], could reduce $90 \%$ of the $\mathrm{CO}_{2}$ emissions for 2050 by the introduction of the concept of near zero energy buildings (NZEB), the refurbishment of the old buildings, the replacement of the fossil fuels, the introduction of renewable energies, and also the recovery of waste energy [1].

At the present time, the average European household space heating consumption accounts for $64.7 \%$, being thus the major consumption; whereas the water heating consumption only accounts for $14.5 \%$ [3]. With the introduction of the Near Zero Energy Building (NZEB) concept, the EU targets to reduce the space heating energy consumption to a great extent. Therefore, the percentage associated to water heating will largely increase and will play a key role in the EU objective of decarbonization for 2050. Nevertheless, and contrarily to the space heating consumption, the water heating consumption 
cannot be reduced by acting over the energy demand without risking the user comfort. Therefore, the only way of reducing the water heating demand consists of using highly efficient technologies, decreasing the energy losses of the system, performing a proper sizing of the integrated components, and applying waste energy recovery strategies to minimize energy losses.

There are many technical solutions in order to recover waste heat but heat pump (HP) technology is the only one that could act as a "heat transformer", getting heat at a given temperature level and supplying heat at the desired temperature level (of course, with the corresponding energy supply). This characteristic will ensure that HPs will play a central role in heating, cooling, and Domestic Hot Water (DHW) efficient applications, as it allows the integration with other heat sources (waste heat, district heating, and the like). In addition, it should be remarked also that it is recognized as a renewable energy resource by the EU [4].

There have been many studies dedicated to increasing the performance of HP technology for DHW, combined with the use of natural refrigerants, especially in the last decade. $\mathrm{CO}_{2}(\mathrm{R} 744)$ has been the most direct solution in heat pumps for DHW applications. Ref. [5] summarizes the different applications of this approach in the residential sector. Nevertheless, other approaches have appeared based in other natural refrigerants, basically hydrocarbons, in the last years. In [6-8], the optimization of a heat pump performance using propane as a refrigerant is analyzed, controlling the subcooling of the system, and others as [9] in which the substitution of R134a in a HP water heater by propane and isobutane (R600a) is analyzed and optimized.

Regarding the waste heat recovery for domestic applications, most works found in the literature only implement the heat recovery from grey water using a heat exchanger [10-15], for instance, in showers. However, the implementation of these kind of systems lose an important part of the wasted energy potential and complementary systems must be installed in order to fulfill the hot water demand. When a HP is used, like in [16], they address this problem acting over the control of the system but they do not address the adaptation of the HP and other components to the system characteristics, losing part of the potential for improvement. When considering a district heating network as a source, an interesting option that is emerging nowadays, as indicated by [17-19], is the combination of ultra-low district heating networks (ULTDH) with a collective HP booster. This option allows to reduce the temperature of the DH network and thus reducing the energy losses as well as increasing the Coefficient of performance (COP) of the HP booster [20].

Considering the HP for DHW production, it is undeniable the high importance and contribution of the thermal energy storage system (TES), as stated in [17] or [18], since it allows the use of small capacity units to cope with relatively high demand peaks. The tandem HP + TES provides a very high efficiency with zero local $\mathrm{CO}_{2}$ emissions, reduces the number of starts-up of the compressor, gives the opportunity to shift generation and demand and hence using low price electricity, and facilitates the integration of renewable energy sources and the recovery of waste heat. When introducing a TES in the system, there are different possibilities, the most common one considered in the literature is the stratified storage tank as stated in [20-28]. The thermal stratification within the water storage tank increases the global energy efficiency of the system compared with other alternatives like the fully mixed storage option $[23,24,27]$ and a bad stratification within the TES system results in a global efficiency drop, as stated in $[25,26]$. Considering the exergy analysis in a TES system, the results indicate that the stratified tank is a more convenient option [29] than a fully mixed tank. According to [30], the stratification increases the TES efficiency and the exergy storage capacity of the TES system; 2.3 times more usable volume is recovered from a perfectly stratified storage tank as stated in [29]. This has made it that it is the most extended option nowadays. However, it should be taken into account that perfect stratification is not possible. Heat transfer by conduction, but also some irreversibilities, like the association to the process of the water going into and out of the tank, tend to break the stratification, but usually are not considered in the reported theoretical results and could be quite important, resulting in a efficiency loss from the expected theoretical values. Other alternatives, like using a constant temperature variable-water-volume tank, could avoid some of these disadvantages of the 
stratified tank, but according to the knowledge of the authors, they have not been deeply analyzed in the literature, probably because the concept of variable volume is commonly associated to open tanks.

In [31], a system employing a tank with variable-water-volume was designed and optimized to minimize the energy consumption while satisfying the instantaneous DHW demand of a set of 20 dwellings. The system uses a HP specially adapted for the production of DHW [31], a variable-water-volume storage tank and a heat recovery unit (HRU) in order to maximize the system global efficiency.

In this research, the influence derived from the way in which the water is stored is going to be analyzed for energy recovery applications, considering a water heat source temperature of $30{ }^{\circ} \mathrm{C}$ which could correspond to an ULTDH network or waste heat from grey water applications. In order to do that, the stratified tank, which is the most extended solution nowadays, is compared with the variable volume tank proposed in [31]. To this purpose, both cases have been simulated and their energy performance from the point of view of the system has been analyzed. The analysis intends to compare both cases under the same conditions. Furthermore, in order to identify the locations of energy degradation, and better understand the results and quantify the usefulness of the energy stored in both tanks, an energy and exergy comparison analysis of both TES options, based on [32], has been performed. Finally, a way to build a variable volume tank in closed real systems will be proposed. The final purpose of the paper is to conclude what is the best TES option for a booster HP system with energy recovery from a low temperature water heat source.

In order to present this work, the article is organized as follows: First, a description of the analyzed cases the model created to study them and the conditions in which the systems were compared is presented. Then, the results section presents the results obtained for each simulation and a comparison among them. Later on, a proposal in order to build a variable volume tank in a closed system and finally the main conclusions of the work are presented. Finally, an Appendix A with an energy and exergy analysis of both tanks has been included which could help to understand from the qualitative point of view the quantitative obtained results of the paper.

\section{System Description}

This section describes the analyzed systems, in order to do that, it is divided in four parts: In the first one, the systems under study are presented. In the second one, the models used to simulate these systems and their corresponding components are described, and finally, in the last two sections, the selected performance parameters and the employed simulation matrix are introduced.

\subsection{Cases Analyzed}

Figure 1a presents the general layout of the conventional solution, HP coupled with TES and HRU, with a stratified storage tank, whereas Figure $1 \mathrm{~b}$ presents the system with the variable-water-volume TES system proposed in [31].
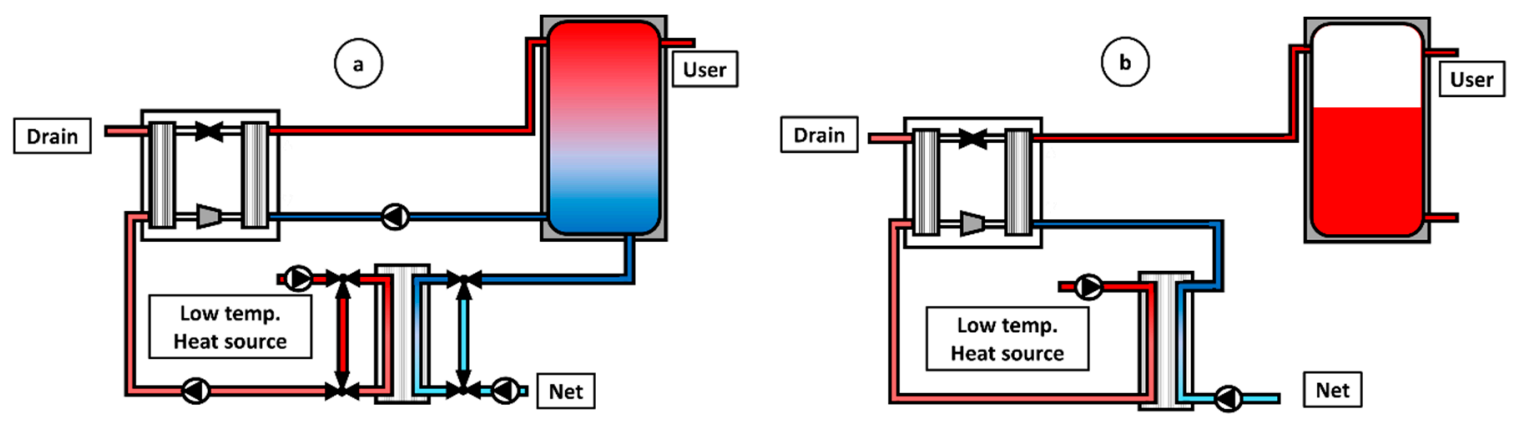

Figure 1. Illustration of the two Thermal Energy Storage Tank cases compared: (a) System with stratified tank and (b) System with variable water volume tank. 
The systems under analysis consists of a HP-DHW production facility with sensible heat storage and a HRU. The main components of both systems are:

- The HRU, which consists of a braze plate heat exchanger (BPHE) that takes profit of the temperature of the heat source to preheat the water coming from the net.

- The thermal energy storage (TES) is a sensible heat storage tank. The two studied TES alternatives are a stratified storage tank (a) and a variable-water-volume storage tank with uniform temperature (b).

- The booster HP that corresponds with the subcooled HP (SHP) developed under the EU project NxtHPG [33], which is able to always work with optimal subcooling.

- $\quad$ The circulation water pumps.

As it is possible to observe in Figure 1, the topology of both cases is different. The variable-water-volume tank case includes the HRU between the water heat source loop and the SHP, whereas the stratified case includes it between the city water net and the tank. In the stratified tank case, it is very convenient to force the water passing through the recovering heat exchanger before entering the tank, since it will give the maximum recovery and will improve the efficiency of the stratification in the tank given that the temperature difference between top and bottom decreases. This layout is not possible in the case of the variable-water-volume tank since the tank has only one inlet, which must be kept at the maximum temperature.

The stratified tank topology has 2 inlets and two outlets and this implies that it has more variability in its operation as the SHP can be switched on but no fresh water is going into the tank (water tank heating) or fresh water can be flowing into the tank but the SHP can be off. These situations are not present in the variable-water-volume tank, as it only has one inlet and one outlet, and when there is fresh water flowing in the tank, the SHP and the BPHE must be active.

In order to perform a fair comparison between both cases, two different operation modes of the stratified case have been considered. Operation mode 1 includes a bypass to the HRU as shown in Figure 1a. This responds to the fact that, in the variable-water-volume system, there is only preheating when the SHP is switched on and also when more heat is extracted from the water heat source in such a way that when the SHP is off and there is fresh water flowing into the tank no heat recovery is applied. This operation mode could be interesting from the point of view of saving heat source use in the situations in which its exploitation is low. Operation mode 2 consists of operating the system without any bypass. In this way, when the SHP is switched off but there exists user demand, a constant water mass flow is kept through the hot circuit of the HRU. This water heat source mass flow will be referred as MWOFF in the following, which means that the HRU is working, and the water entering the tank at the bottom is first heated up thanks to the heat recovery. The value MWOFF is a parameter of the system.

\subsection{Integrated System Model}

Transient system simulation tool (TRNSYS) [34] has been used to model and analyze the different cases. The model presented in [31] was used for the variable-water-volume case and the stratified model was created using the variable-water-volume model as basis. The features and modeling of the main components of the systems and of the control are commented in the following.

- $\quad$ Subcooled Heat Pump (SHP)

- Water-to-water SHP.

- Works with R290 (Propane) as refrigerant.

- Is able to work with optimal subcooling, as explained in [6] with the objective of taking profit of the high temperature lift in the DHW application.

- The SHP has been experimentally tested and fully characterized in the laboratory, as reported in [35]. 
- From the experimental results, a polynomial regression model was generated to characterize the SHP performance across the whole range of possible operation conditions. The maximum deviation between the simulated and the experimental results is lower than $4 \%$, so the model is able to simulate the SHP performance very accurately.

- $\quad$ TES tanks

The stratified tank was simulated with TRNSYS type 60, whereas the variable-water-volume tank was simulated using TRNSYS type 39. The height of the inlets and outlets of the stratified tank were defined according to those of typical commercial tanks for that application: inlet to the tank from the SHP at $90 \%$ of the total height, the outlet of the tank to the SHP at 10\%, the inlet to the tank from the net at $5 \%$, and finally the outlet to the user at $95 \%$. The variable-water-volume tank has only one inlet from the SHP and one outlet to the user. The peculiarities of the variable-water-volume tank model in comparison with the stratified tank, are that first the water temperature inside is considered uniform, although it is changing with time, depending on the mixing between the inlet flow coming from the SHP, and the outgoing flow going the user, and the heat losses to the ambient; and second, that the volume of water inside the tank is variable, depending on balance between the DHW production from of the SHP and the DHW demanded from the user.

Regarding the shape of the tanks, an aspect ratio of 4 was considered for both storage tanks. This value is usual in commercial tanks and commonly used in stratified storage tank models. A value of $0.8 \mathrm{~W} / \mathrm{m}^{2} \mathrm{~K}$ was considered in accordance with the maximum heat loss coefficient allowed by Spanish regulation. Regarding the connection between the tank and the SHP, a direct connection has been considered in this study. The effects of an indirect connection could also be studied as it has been done in [36].

The TRNSYS model of the stratified tank considers a de-stratification conductivity value that accounts for the conduction losses. TRNSYS mathematical reference recommends calculating this value by using Equation (1), the value obtained and used in the model accounts for $2 \mathrm{~W} / \mathrm{mK}$ (See [37,38] for a detailed explanation of the calculation method):

$$
k_{\text {destratification }}(\mathrm{W} / \mathrm{mK})=k_{\text {tank-wall }} \cdot \frac{A_{\text {tank }}}{A_{\text {fluid }}},
$$

where $k_{\text {tank-wall }}$ is the thermal conductivity of the wall tank, $A_{\text {tank }}$ is the cross-sectional area of the tank wall, and $A_{\text {fluid }}$ the one from the fluid in the tank.

- HRU

The BPHE was modeled with the NTU-effectiveness approach, considering an effectiveness of 0.75 in the nominal point. The characteristic UA value is evaluated at the nominal point and kept constant along the simulations. NTU varies depending on the actual instantaneous mass flow rates.

- Other components

The circulation pumps were modeled with TRNSYS type 742. The pressure losses in each circulation loop were considered negligible in comparison with the pressure drop across the heat exchangers. A correlation for water pressure drop across the HRU, the condenser, and evaporator was developed from the corresponding catalogue data. The model of the circulation pumps allowed the estimation of the circulation pumps consumption given the pressure drop in their respective loop.

The models also included an anti-scalding mixer valve with the net at the outlet of the tanks in order to keep the required $45^{\circ} \mathrm{C}$. 
- User demand

The user demand profile chosen for the study consists of 20 multifamily houses with an average occupancy rate of 1.95 people per house. The profile used for the study was obtained with the tool DHWcalc [39] and it is explained in detail in [31].

\section{Control}

A different control strategy was followed in each case. The control of the stratified case consists of a temperature control that is performed through a hysteresis controller that commands the set-point temperature of $60^{\circ} \mathrm{C}$ in the selected node of the storage tank. The upper dead band was fixed at $63^{\circ} \mathrm{C}$ and the lower dead band is fixed at $60{ }^{\circ} \mathrm{C}$, considering $60{ }^{\circ} \mathrm{C}$ as the minimum system temperature since the installation must satisfy the legionella regulation [40]. Figure 2 represents graphically the operation of the hysteresis controller. In the upper part of the figure, the evolution of the temperature at the control node has been represented. As it can be observed, the temperature is well kept between 60 and $63{ }^{\circ} \mathrm{C}$ during operation. The position of the control of temperature in the tank is an important variable, therefore it was considered as an optimization variable.

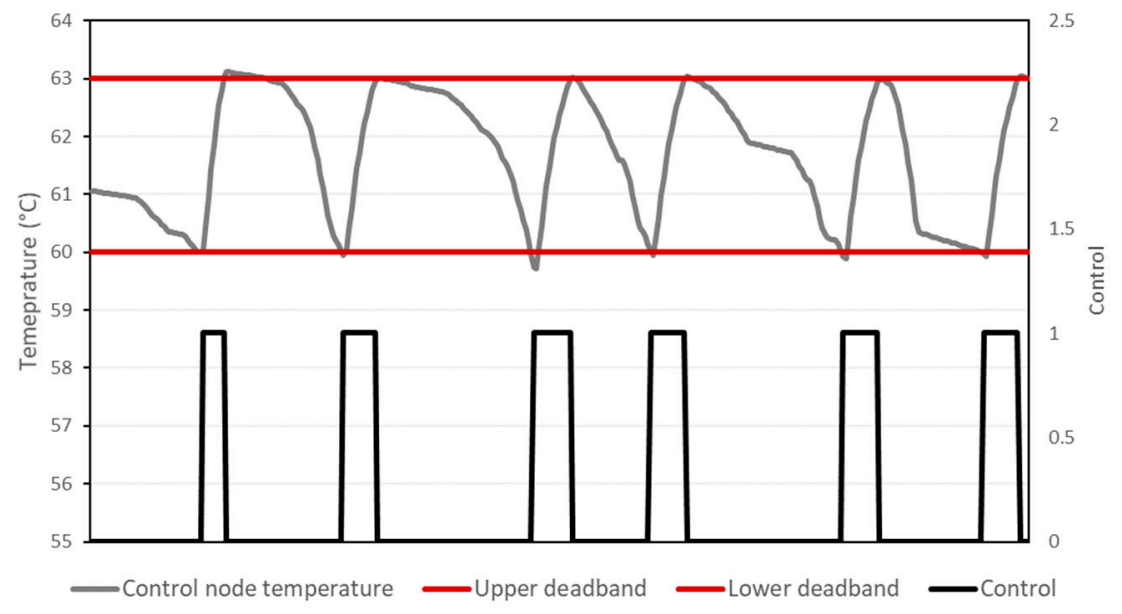

Figure 2. Description of the hysteresis controller.

The tank model was composed of 15 levels, three variable levels were considered enough to study the influence of this parameter on the system performance: top node of the tank, fourth node from the top ( $75 \%$ of height), and seventh node ( $50 \%$ of height), as it is schematically shown in Figure 3.

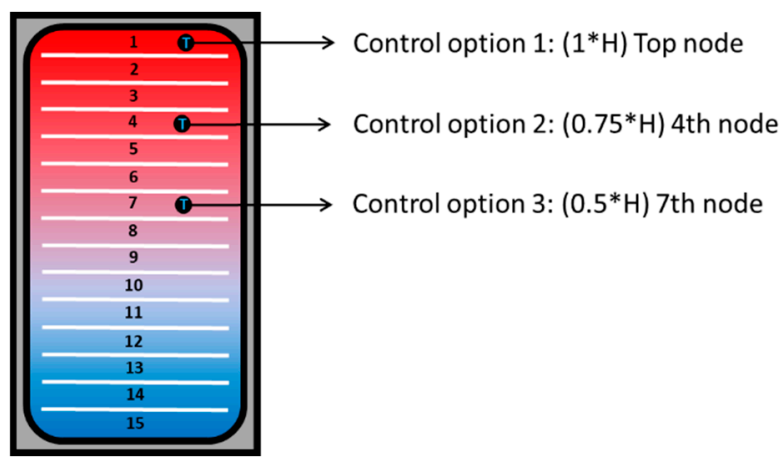

Figure 3. Control options considered for the stratified tank case.

The water outlet temperature at the condenser was set to $63{ }^{\circ} \mathrm{C}$. This responds to the fact of maintaining a minimum temperature in the tank of $60^{\circ} \mathrm{C}$, which is the control setpoint temperature. 
The simulations performed showed $63^{\circ} \mathrm{C}$ as the minimum outlet condenser temperature that achieves this requirement stably.

However, the variable-water-volume case needs also to control the volume of water stored inside the tank, thus requiring a switch to stop the filling and the SHP use when the tank is full, and to fill in and switch on the SHP when the tank reaches a low level limit, which could lead to emptying the tank if the DHW demand follows. For this purpose, a parameter alpha defined as the percentage of the minimum volume inside tank, respect to the tank total volume, at which the SHP is switched on, was introduced in the model as an optimization variable.

\subsection{Model Restrictions and Energy Performance Indicators}

In order to compare the different systems, four indicators have been selected: the system global efficiency appointed as SPFuser (the system is designed to minimize this parameter), the SPF1, the total energy recovered at the BPHE, and the total energy used from the low temperature heat source:

$$
\begin{gathered}
S P F_{\text {user }}=\frac{Q_{\text {user }}}{W_{H P \text { compressor }}+W_{\text {auxiliaries }}}, \\
S P F_{1}=\frac{Q_{H P \text { condenser }}}{W_{H P \text { compressor }}} .
\end{gathered}
$$

The seasonal performance factor for the user $\left(S P F_{\text {user }}\right)$ is defined as the ratio between the useful heat supplied to the user $\left(Q_{u s e r}\right)$ and the total energy consumption of the system $\left(W_{H P}\right.$ compressor $\left.+W_{\text {auxiliaries }}\right)$ as stated in Equation (2). The seasonal performance factor of the SHP $\left(S P F_{1}\right)$ is defined as the ratio between the heat supplied by the SHP condenser $\left(Q_{H P}\right.$ condenser $)$ and the energy consumed by the SHP compressor $\left(W_{H P}\right.$ compressor $)$ as stated in Equation (3). Finally, the total energy recovered accounts for the energy recovered in the HRU and the total energy used from the low temperature heat source for the energy extracted from the heat source considering the minimum system temperature as reference $\left(10^{\circ} \mathrm{C}\right)$.

This study focuses on DHW production systems that employ a low temperature water stream as heat source, as for instance, grey water or a ULTDH. In order to reduce the number of input variables, the water temperature of the water stream has been considered as $30^{\circ} \mathrm{C}$ and the temperature of the city water as $10^{\circ} \mathrm{C}$. Other combinations of temperatures could influence the absolute results but not the relative comparison among the options considered or the main conclusions.

Several restrictions have been added in the model in order to guarantee that all optimal solutions found also satisfy the user comfort (water supply at $45^{\circ} \mathrm{C}$ ) and the system reliability. The restrictions are:

- Maximum value for the annual percentage of discomfort of $0.05 \%$, evaluated as shown in Equation (4). Where $m_{\text {user }}\left(T<45^{\circ} \mathrm{C}\right)$ corresponds with the mass flow rate over $45^{\circ} \mathrm{C}$ and $m_{\text {user }}$ with the total mass flow rate:

$$
\text { Annual }_{\text {discomfort }}=\frac{\sum m_{\text {user }\left(T<45^{\circ} \mathrm{C}\right)}}{\sum m_{\text {user }}}<0.01
$$

- The total amount of minutes along the year during which the comfort was not reached is limited to a maximum value of $30 \mathrm{~min}$ per year, which corresponds to $5 \mathrm{~s}$ of discomfort per day for each hour of the day. This value is quite small compared to comfort requirements imposed in other applications like heating and cooling of spaces in which total time percentages along the year are defined, but it should be done in that way as the demand profile along the day is quite focused in certain periods.

- Limitation of the number of starts per hour of the SHP to a maximum of 9. This is the usual limitation stated by the compressor manufacturers. 


\subsection{Optimization Variables and Study}

According to the main objective of the study: minimization of the energy consumption for a given DHW demand, the optimization variables selected for the study were the size of the HP and the volume of the tank; as well as, the position of the sensor in the stratified storage tank and the value of MWOFF if applicable, and finally, the parameter alpha for the variable-water-volume case. The levels of the variables, selected to perform the optimization study, are summarized in Table 1. The percentage in the SHP size column indicates the percentage of the size considered in regard to a maximum considered size. The maximum values for the SHP size, the tank volume, the water flowrate MWOFF, and the ALPHA value were considered as $47 \mathrm{~kW}, 1000 \mathrm{~L}, 10,000 \mathrm{~kg} / \mathrm{h}, 90 \%$, respectively. The optimization study was performed for each case estimating the performance of the full factorial combination of parameter levels shown in Table 1. Additionally, for the stratified tank case, the study covered each the following system options:

- Without limitation in the water heat source.

- Stratified with bypass.

- Stratified without bypass.

- Limitation in the water heat source.

- Limitation on the energy recovered from the water heat source.

- Limitation in the used amount of water heat source.

Table 1. Optimization variables and steps considered.

\begin{tabular}{|c|c|c|c|c|c|c|}
\hline \multicolumn{3}{|c|}{ Variable Water Volume Case } & \multicolumn{4}{|c|}{ Stratified Case } \\
\hline Alpha & Volume & SHP size & Mwoff & Volume & SHP Size & Control Node \\
\hline$\%$ & Liters & Heating kW & $\mathrm{kg} / \mathrm{h}$ & Liters & Heating kW & - \\
\hline $10 \%$ & 80 & $2.4 \mathrm{~kW} \mathrm{(5 \% )}$ & 50 & 80 & $2.4 \mathrm{~kW} \mathrm{(5 \% )}$ & 1 st \\
\hline $20 \%$ & 100 & 4.7 kW (10\%) & 100 & 100 & 4.7 kW (10\%) & 4 th \\
\hline $30 \%$ & 200 & 9.4 kW (20\%) & 200 & 200 & 9.4 kW (20\%) & 7th \\
\hline $40 \%$ & 300 & $14.1 \mathrm{~kW}(30 \%)$ & 300 & 300 & $14.1 \mathrm{~kW}(30 \%)$ & - \\
\hline $50 \%$ & 400 & $18.8 \mathrm{~kW}(40 \%)$ & 400 & 400 & $18.8 \mathrm{~kW}(40 \%)$ & - \\
\hline $60 \%$ & 500 & $23.5 \mathrm{~kW}(50 \%)$ & 500 & 500 & $23.5 \mathrm{~kW}(50 \%)$ & - \\
\hline $70 \%$ & 600 & $28.2 \mathrm{~kW}(60 \%)$ & 1000 & 600 & $28.2 \mathrm{~kW}(60 \%)$ & - \\
\hline $80 \%$ & 700 & $32.9 \mathrm{~kW}(70 \%)$ & 2000 & 700 & $32.9 \mathrm{~kW}(70 \%)$ & - \\
\hline $90 \%$ & 800 & $37.6 \mathrm{~kW}(80 \%)$ & 2500 & 800 & $37.6 \mathrm{~kW}(80 \%)$ & - \\
\hline - & 900 & $42.3 \mathrm{~kW}(90 \%)$ & 5000 & 900 & $42.3 \mathrm{~kW}(90 \%)$ & - \\
\hline - & 1000 & $47 \mathrm{~kW}(100 \%)$ & 10000 & 1000 & $47 \mathrm{~kW}(100 \%)$ & - \\
\hline
\end{tabular}

In the cases with the water heat source limitation, the limitation was fixed to the values obtained in the variable-water-volume case.

From the practical point of view, the cases in which there is no limitation in the availability of the heat source would correspond to a booster HP coupled with and ULTDH network. Whereas the cases with a limitation in the water heat source are more similar to an application such as grey water energy recovery since the use from the low temperature heat source is limited.

\section{Results}

This section has been divided in three parts. It should be remarked that there is no optimum solution but a pareto front of solutions that have a similar final minimum energy consumption. Therefore, the comparison among the different cases has been made for the solution with the minimum SHP size.

\subsection{User Demand Profile Sensitivity Analysis}

In order to be able to provide general conclusions of applicability, an analysis of the obtained results to the demand profile dependence was performed. The objective consisted of concluding whether the profile demand would influence the solution found. 
To this purpose, different DHW demand profiles have been created using DHWcalc [39]. These profiles are generated randomly but with a fixed value of liters/year. The simulations were performed for 10 years considering four different profiles, 3 of them were different, 1 year profiles repeated during the 10 years period, and the last one was composed of 10 year profile in which each year was different. The cases chosen are the optimal ones for the variable-water volume and the stratified case without bypass and without limitations. Table 2 shows the results obtained for all the cases from the energy point of view, and it is seen that no significant differences are observed among the different cases, depending on the stochasticity associated to the DHW generation program. Therefore, the obtained system configurations and their associated energy consumption will not depend significantly on the stochasticity associated to the DHW demand.

Table 2. Demand profile influence analysis results.

\begin{tabular}{ccccc}
\hline & \multicolumn{2}{c}{ SPF1 } & \multicolumn{2}{c}{ SPFuser } \\
\cline { 2 - 5 } & Stratified Case & Variable-Volume Case & Stratified Case & Variable-Volume Case \\
\hline 1 year profile: P1 & 5.80 & 5.77 & 7.79 & 7.77 \\
1 year profile: P2 & 5.80 & 5.77 & 7.83 & 7.78 \\
1 year profile: P3 & 5.79 & 5.77 & 7.79 & 7.78 \\
10 year profile & 5.79 & 5.77 & 7.79 & 7.78 \\
\hline
\end{tabular}

\subsection{Obtained Results for Each Case}

This subsection presents the obtained results for the cases presented in Table 1 in detail.

\subsubsection{Variable-Water-Volume Case Results}

The results corresponding to the variable-water-volume case are presented in Figure 4. It shows the results for the different values of the optimization variables: SHP size and tank volume are illustrated in a map for the value of the optimization variable alpha of 0.4. The performance map for the annual energy consumption and the SHP working hours are included in Figure 4. However, the rest of the maps for all the alpha values have been also considered for the conclusions here included.

(a) Annual energy consumption

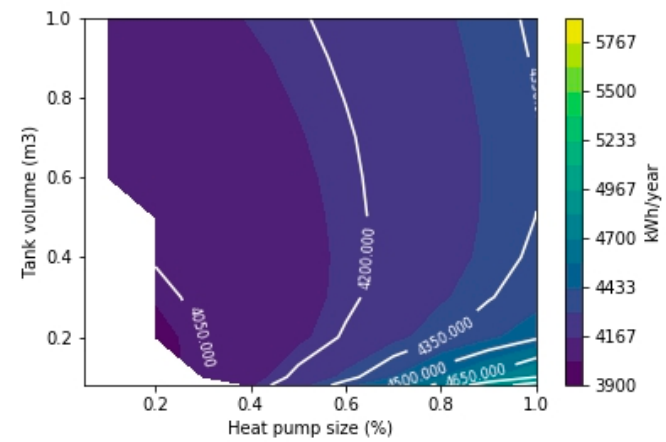

(b) HP working hours

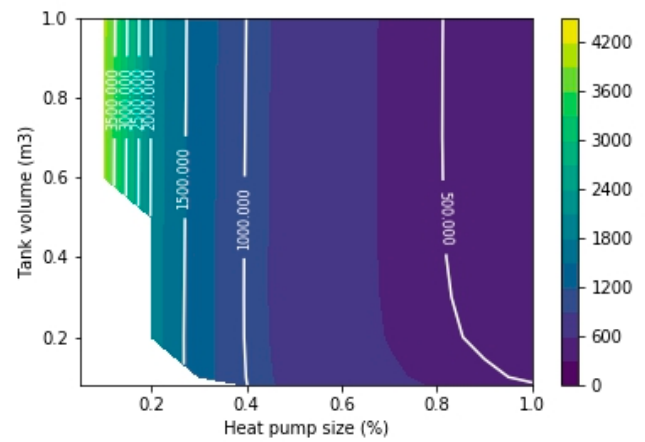

Figure 4. Performance maps of the annual energy consumption and working hours for the values of Subcooled heat pump and tank size and an alpha value of 0.4 of the variable-water-volume case.

As it has been commented, the results show that there does not exist a best case but a flat map of best cases with a reduced difference among them. The performance maps show the tendencies commented in the following:

- The white region corresponds to SHP-volume combinations which do not satisfy the comfort criteria.

- SHP size: the maximum system performance is reached for the low SHP sizes. However, the tank size should be also designed in agreement with it to minimize the energy consumption. 
- Tank volume do not have so much impact as the SHP in the energy consumption of the system.

- When the SHP increases its size, the use of small tanks penalizes the efficiency of the system.

- For each SHP size, exists an optimum tank volume for a fixed value of the parameter alpha. In that sense, for a given SHP size, the use of a tank smaller than the optimum will penalize more the system efficiency than the use of a tank larger than the optimum.

- As the SHP size is reduced, the number of SHP operation hours increases, the tank volume has a limited influence on the working hours and for the same SHP size, this time increases slightly with the increase of the tank volume.

- Alpha: This parameter affects the energy consumption indirectly. Although it does not have a major relevance in the total energy consumption (see Figure 5), as its value increases, the minimum tank volume increases and in this way, more combinations of SHP-tank sizes are included in the cases that comply with comfort conditions. This fact allows to include as feasible solutions more cases with low SHP-tank sizes that usually correspond with the lowest energy consumption cases. Therefore, although alpha does not have a direct influence on the energy consumption, to select high alpha values allows to include in the possible configurations SHP-tank volumes smaller which tends to increase the efficiency of the system.
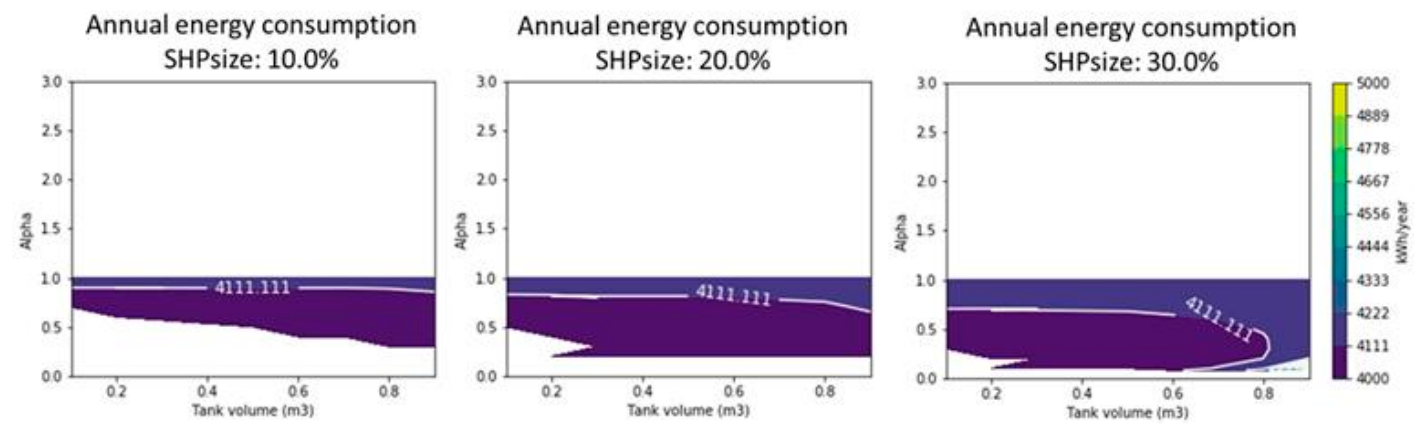

Figure 5. Annual energy consumption as a function of the tank volume and alpha value for a subcooled heat pump size of $10 \%(2.35 \mathrm{~kW}), 20 \%(4.7 \mathrm{~kW})$, and $30 \%(9.4 \mathrm{~kW})$ (from left to right).

\subsubsection{Stratified Case Results without Water Heat Source Limitation}

\section{Stratified Case Results with Bypass}

The results corresponding to the stratified case with bypass, considering that there is no energy recovery when the SHP is switched off, are presented in Figures 6-8. In them, the results for the different values of the optimization variables: SHP size and tank volume for the 1st, 4th, and 7th node, respectively, are illustrated. The performance map for the annual energy consumption and the SHP working hours are included for each case.

Similarly, to the variable-water-volume, the best results are obtained for the lowest values of SHP size dominates over the tank size from the energy consumption point of view, however in this case, the tank volume has a higher influence on the energy consumption of the system. Regarding the control node, the best results are obtained for the highest position. However, as low is the position of the control node in the tank, there are more SHP-tank combinations satisfying the comfort restrictions imposed to the problem. Thus, it is possible to conclude that the highest position for the control node is the optimal one but for these cases, the design of the system is more critical, as the allowed tank and SHP sizes are more restricted. 
(a) Annual energy consumption

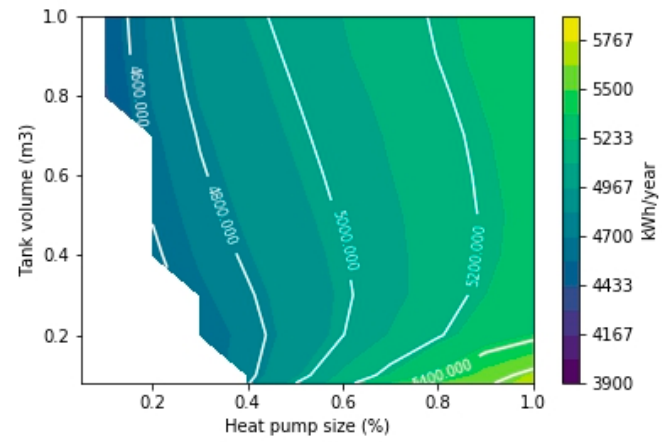

(b) HP working hours

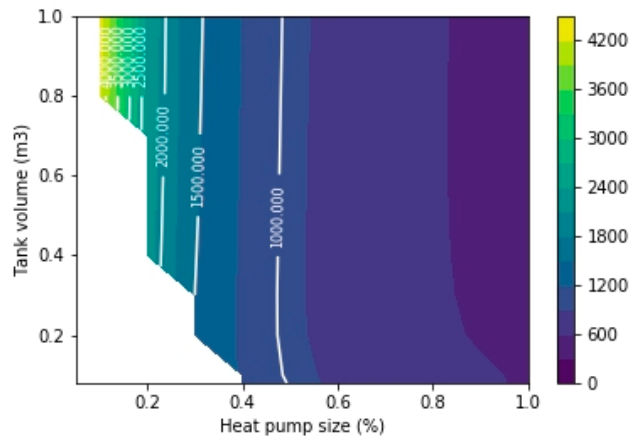

Figure 6. Performance maps for the control node placed in the 1st node of the annual energy consumption and working hours for the values of SHP and tank size.

(a) Annual energy consumption

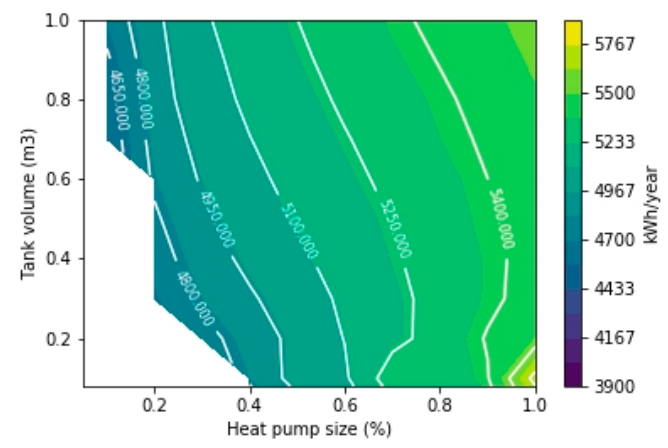

(b) HP working hours

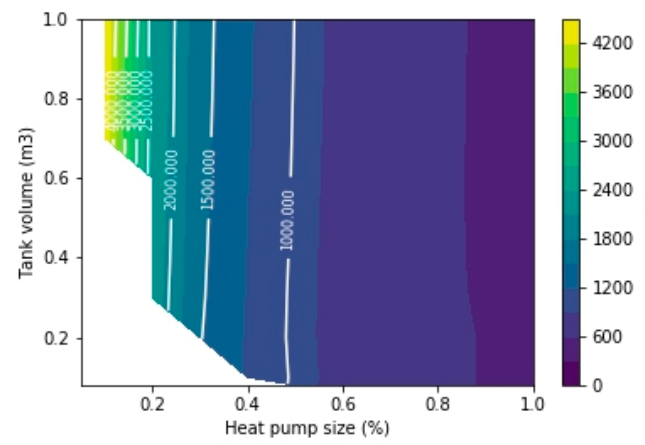

Figure 7. Performance maps for the control node placed in the 4th node of the annual energy consumption and working hours for the values of SHP and tank size.

(a) Annual energy consumption

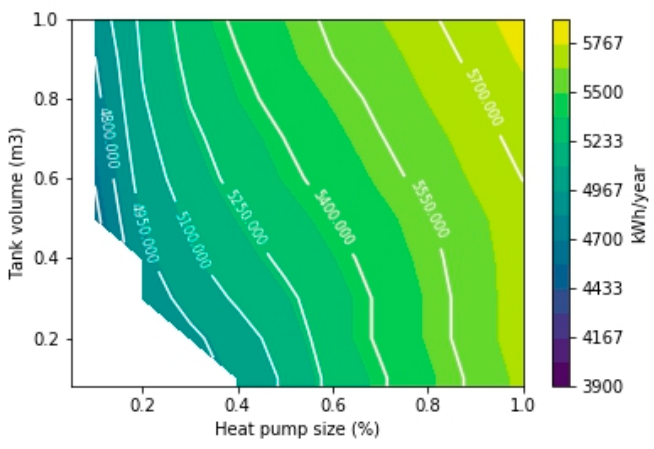

(b) HP working hours

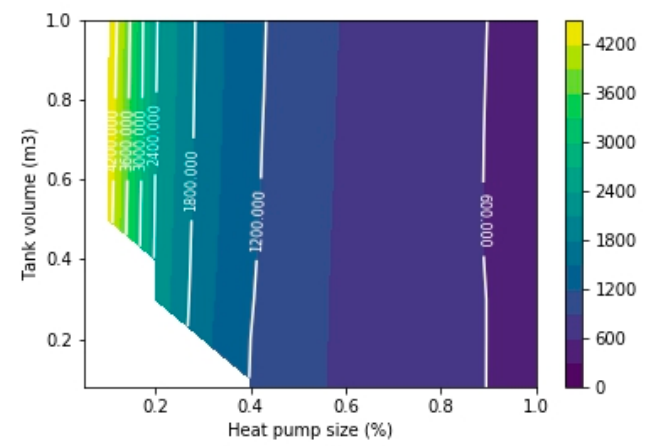

Figure 8. Performance maps for the control node placed in the 7th node of the annual energy consumption and working hours for the values of SHP and tank size.

It is observed that the number of operating hours as well as the energy consumption of the system is significantly higher than in the variable-water-volume case. This is a consequence of the fact that in this system typology, there are operation modes in which the SHP is not working and therefore, water from the net is entering directly to the tank without any preheating. This has the advantage of saving heat source water, but on the other side, the energy consumption is penalized and the heat pump has to work more hours in such a way the water saving is not so important as expected.

\section{Stratified Case Results without Bypass}

The results corresponding to the annual energy consumption and to the working hours are presented in Figure 9 for the case in which the control is performed in the node 1 which corresponds 
to the higher efficiency, the results corresponding to the other node positions are not shown as the obtained trends are similar to the previous case.

It should be noted that in this case, the mass flow rate (MWOFF) circulating through the recuperator when the SHP is off must be determined. As it is indicated in Table 1, a parametric study about the influence of this value in the total energy consumption of the system has been performed and the results shown in Figure 9 correspond to a MWOFF value of $2000 \mathrm{~kg} / \mathrm{h}$, which has been the optimum value obtained from the parametric study.

The results show similar trends to the variable-water-volume tank. The best results are obtained for the lowest values of SHP-tank size, however it is observed that for a given SHP size, the tank volume should be larger. Regarding the working hours of the SHP are similar to the variable-water-volume case. Concerning the MWOFF value, the system global efficiency increases as this value increases due to an increase on the energy recovered, but also the energy consumed from the circulation pumps increases. Thus, there exists an optimum around $2000 \mathrm{~kg} / \mathrm{h}$ over which the energy recovered collapses but the energy consumption from the circulation pumps continues increasing. The best stratified case shows a $0.8 \%$ lower energy consumption compared with the variable-water-volume case but requires $87 \%$ more energy from the low temperature heat source.

(a) Annual energy consumption

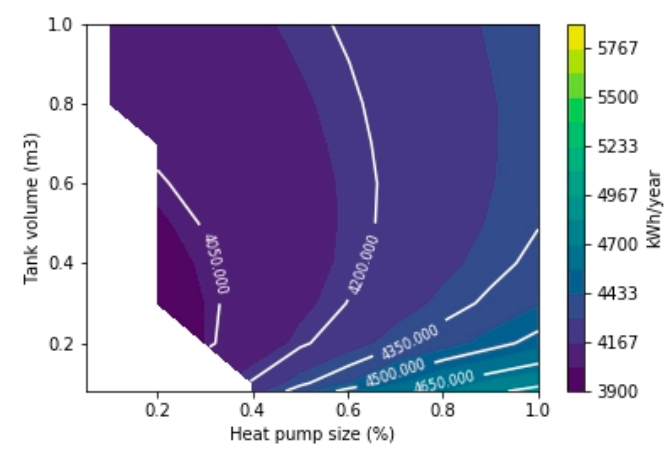

(b) HP working hours

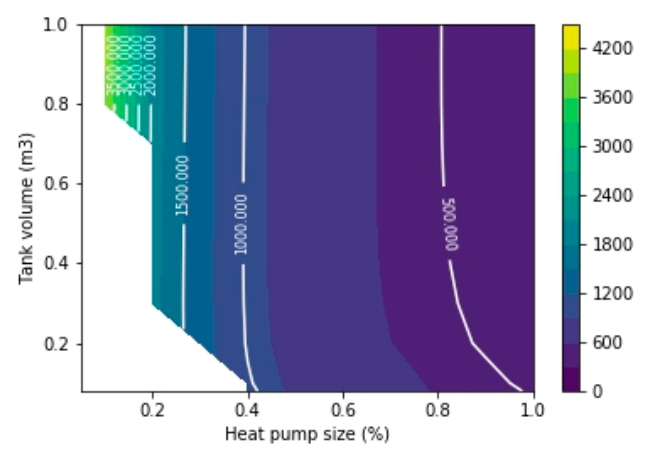

Figure 9. Performance maps for the control node placed in the 1st node and a MWOFF value of $2000 \mathrm{~kg} / \mathrm{h}$ of the annual energy consumption and working hours for the values of SHP and tank size.

In the next subsection, the energy from the low temperature heat source of the stratified tank systems is going to be limited to the values obtained for the variable-water-volume tank.

\subsubsection{Stratified Case Results with Water Heat Source Limitation}

For the limitation of water availability, two options have been analyzed. First, the same amount of energy recovered from low temperature heat source than in the variable-water-volume tank was imposed on the model. Later on, the use of the same amount of water was considered, in this case to simulate that behavior, the scheme shown in Figure 10 was used. According to the results obtained previously, the bypass configuration is not going to be analyzed for these cases.

\section{Limitation in the Energy Recovered by the System}

The value at which the restriction was imposed is $88,060 \mathrm{kWh}$, which corresponds to the one required in the variable-water-volume case. In this way, the stratified cases with a higher energy use than the limited settled will be discarded.

Figure 11 represents the energy consumption as a function of SHP size and tank volume for several values of MWOFF. The results show that the annual energy consumption of the system increases until it reaches a value of $200 \mathrm{~kg} / \mathrm{h}$, maintaining the space area of possible configurations of SHP-tank size and later on, the energy consumption changes the trend with MWOFF and begins to decrease slowly with the increase of MWOFF. In addition, it is observed that the space area of possible system configurations is reduced. 


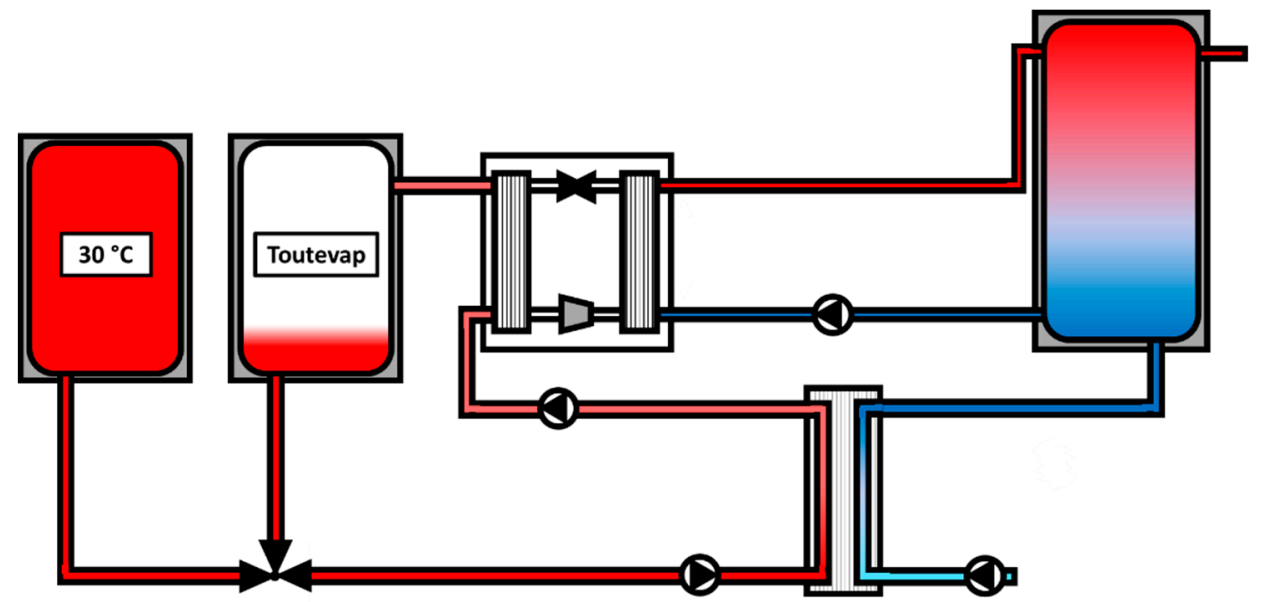

Figure 10. System configuration arranged to limit the energy use from the hot network as a variation in the system.

Annual energy consumption MWOFF: 100.0

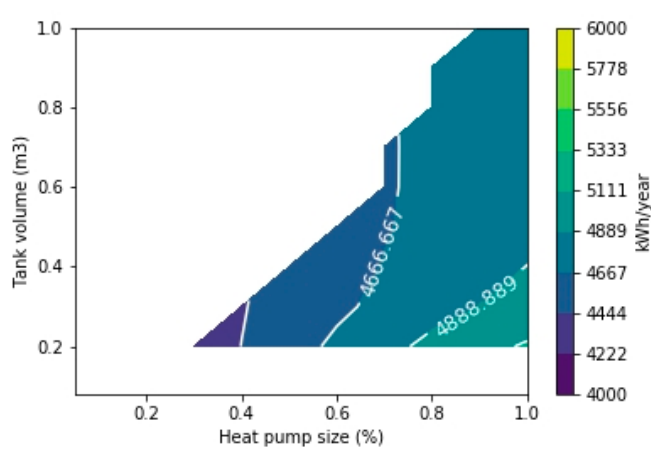

Annual energy consumption MWOFF: 200.0

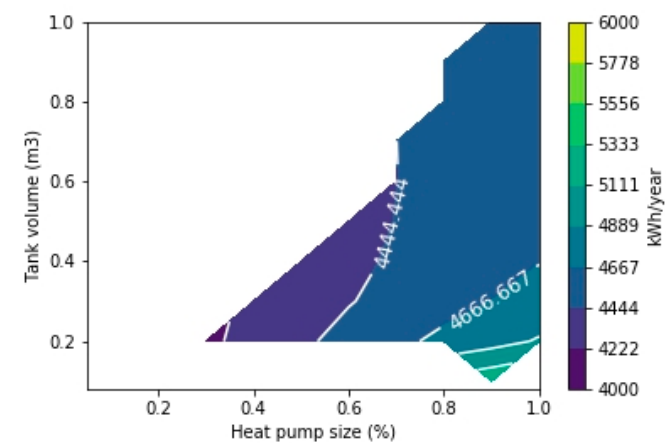

Annual energy consumption MWOFF: 400.0

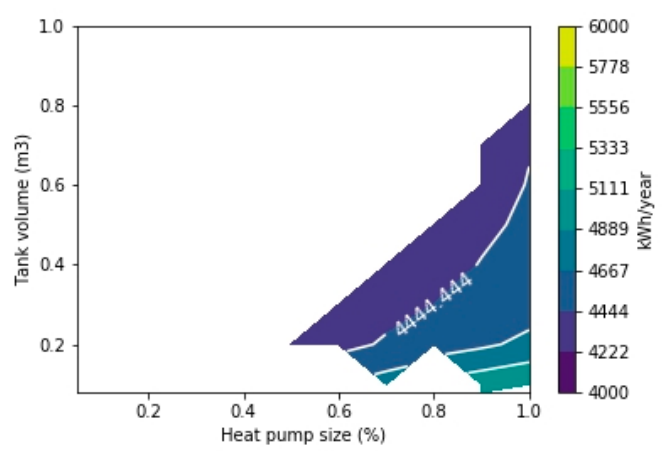

Annual energy consumption MWOFF: 50.0

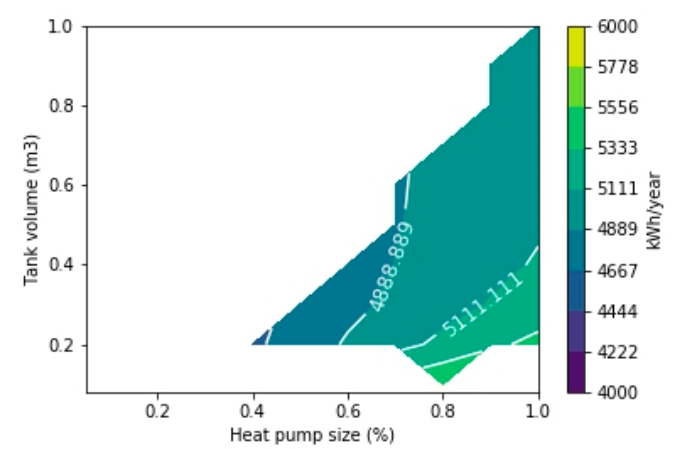

Annual energy consumption MWOFF: 300.0

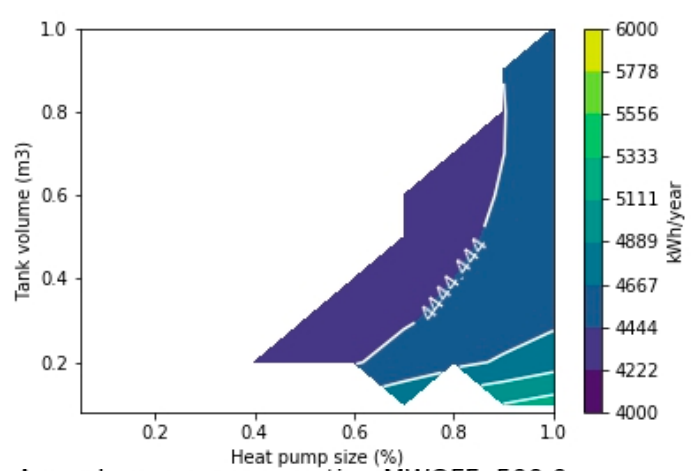

Annual energy consumption MWOFF: 500.0

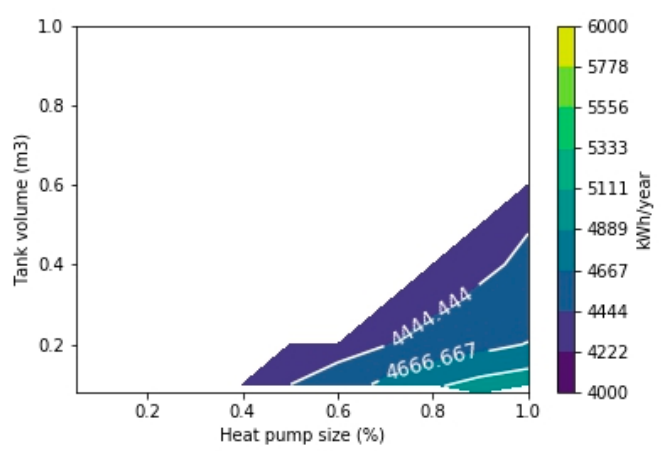

Figure 11. Annual energy consumption as a function of tank volume and SHP size for the stratified system without by-pass when the energy availability is limited for different MWOFF values. 
Figure 12, the results for the annual energy consumption and the SHP working hours are represented. All these results have been presented for the best value of the optimization variable MWOFF $(200 \mathrm{~kg} / \mathrm{h})$.

(a) Annual energy consumption

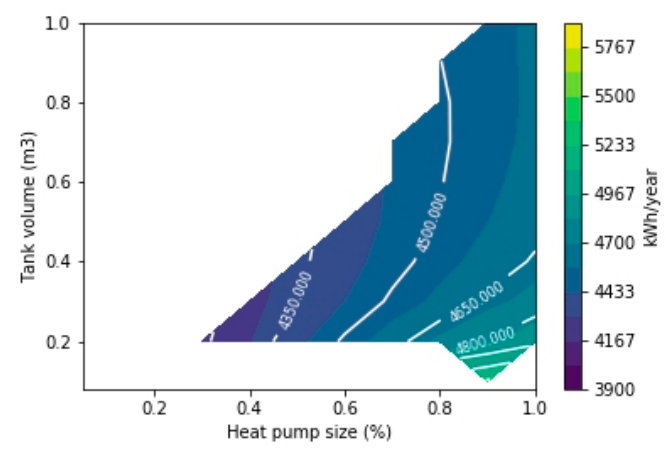

(b) HP working hours

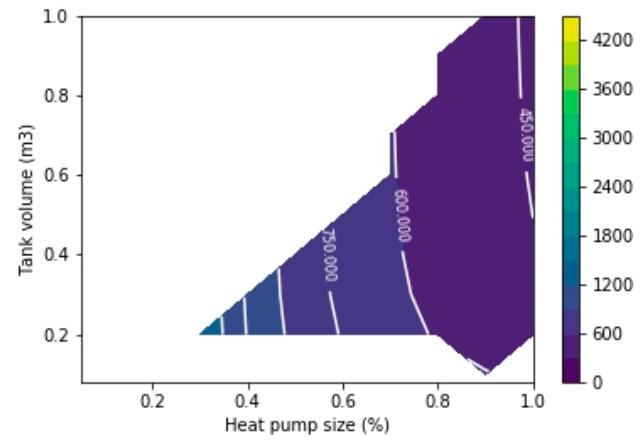

Figure 12. Performance maps for the control node placed in the 1st node and a MWOFF value of $200 \mathrm{~kg} / \mathrm{h}$ considering sewage water limitation as a restriction of the annual energy consumption and working hours for the values of SHP and tank size.

Regarding the observed trends, several comments can be done:

- There is a significant reduction of the amount of system configurations (SHP-tank size able to satisfy the comfort requirements).

- The size of the SHP required is larger than when there is no limitation in the energy source.

- For a given SHP size, the range of water tanks compatible with the comfort requirements is reduced. This will imply that the system will be more sensible to design parameters.

- For a given SHP size, the optimum tank volume is the smaller tank compatible with the comfort restrictions.

- The value of MWOFF has been significantly reduced (approximately $200 \mathrm{~kg} / \mathrm{h}$ ).

- With this limitation there is a total energy consumption increase of $5 \%$ compared to variable-water-volume case with the same energy use from the source.

- The number of operating hours of the SHP has also increased compared to the previous case in which there was no limitation in the energy recovered from the water heat source.

Limitation Total Water Use of the System

In order to analyze the restriction on the low temperature heat source in such a way that the water mass flow is limited but not the energy use, the system configuration shown in Figure 10 has been arranged. The daily water use from the low temperature heat source of the variable-water-volume case has been used as the daily limit. While this limit is not reached, it was considered to store the energy at the outlet of the evaporator of the SHP. In this way, when the daily limit is reached, the hot water network flow at $30^{\circ} \mathrm{C}$ is stopped and the system could take the water from the tank where the outlet of the SHP evaporator has been stored instead of taking it from the network at $10^{\circ} \mathrm{C}$, as shown in Figure 10.

In Figure 13, the results for the annual energy consumption and SHP working hours has been represented as a function of the SHP-tank size for the MWOFF value of $300 \mathrm{~kg} / \mathrm{h}$.

Regarding the obtained results for this case, the following statements can be done:

- The map of possible solutions is similar to the obtained for the stratified cases without any limitation in the heat source.

- The total energy use from the water has increases in $10 \%$ compared to the variable-water-volume case.

- The energy consumption in this case is higher than for the variable-water-volume case. 
- The number of working hours of the SHP is higher than for the variable-water-volume case.

(a) Annual energy consumption

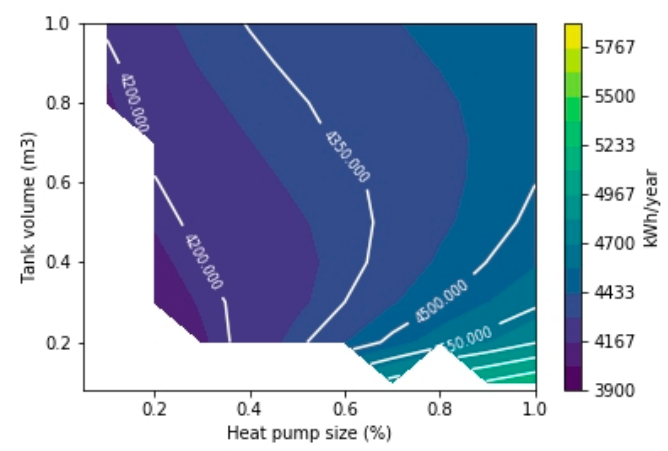

(b) HP working hours

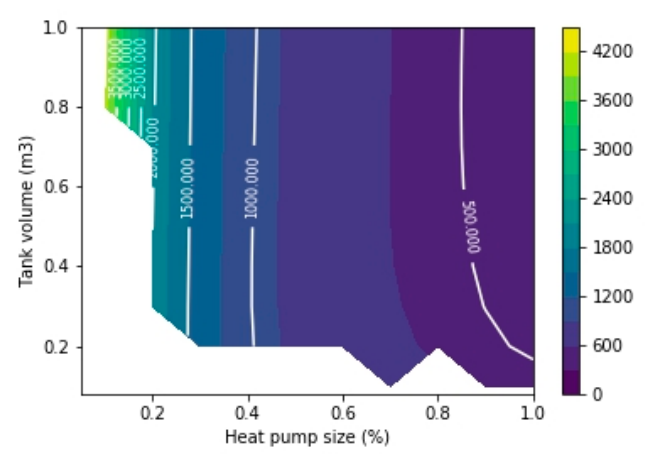

Figure 13. Performance maps for the control node placed in the 1st node and a MWOFF value of $300 \mathrm{~kg} / \mathrm{h}$ considering sewage water limitation as a restriction of the annual energy consumption and working hours for the values of SHP and tank size.

\subsection{Comparison Results}

In this subsection, a comparison among the solutions for the different cases is presented. Table 3 summarizes the obtained results for one specific solution in such a way that the comparison could be made in a clear way. The table includes the results of the optimization variables as well as the energy performance indicators selected (see Section 2). Among the different values for the minimum energy consumption, the solution with the smaller SHP size is presented. In some cases, there are solutions in which the minimum SHP implies a significant increase of the tank volume, for those cases two different size alternatives have been presented.

The comparison between the different cases shows that variable-water-volume tank requires a smaller system (tank and SHP) than stratified system. This is a consequence of the better energy storage strategy of this type of tank. A more detailed explanation about this point is found in the annex, where an energy and exergy analysis of both tank configurations have been done. In that analysis, it is demonstrated that although the energy content of both tanks is similar, the exergy of the variable-water-volume tank is significantly higher $(8 \%)$, allowing a volume reduction of it. For the calculated cases, the variable-water-volume tank requires half the volume of the stratified tank and the SHP can work with $33 \%$ lower capacity.

From the point of view of energy efficiency, when the by-pass is present, the reduction in the energy efficiency of the system is very significant, and as the SHP is working for a longer time period, the amount of used heat water source is also higher than in the stratified cases, therefore from these results it can be concluded that the water has be to preheated before entering in the tank in all the situations. The stratified tank requires significantly higher amount of low temperature heat from the source $(87 \%)$ than the variable-water-volume tank in order to have a similar efficiency.

For the same energy use from the low temperature heat source, the stratified system with the proper control has a reduction in energy efficiency of $3.6 \%$ compared to the variable-water-volume tank. This difference can be reduced to almost $2 \%$ but in that case, $10 \%$ more of energy from the water heat source must be used. 
Table 3. Results of the performance indicators selected for the best 10 cases of the stratified case without bypass and a restriction in the energy used from the hot network.

\begin{tabular}{|c|c|c|c|c|c|c|c|c|c|c|}
\hline Case & SHP Size & Volume & Alpha & $\begin{array}{l}\text { Control } \\
\text { Node }\end{array}$ & MWOFF & $\begin{array}{c}\text { Electric } \\
\text { Consumption }\end{array}$ & SPF1 & SPFUSER & $\begin{array}{c}\text { Energy Recovered } \\
\text { HRU }\end{array}$ & $\begin{array}{c}\text { Hot Network } \\
\text { Energy Consumed } \\
\text { at } 30^{\circ} \mathrm{C}\end{array}$ \\
\hline- & $\%$ & $\mathrm{~m} 3$ & $\%$ & - & $\mathrm{kg} / \mathrm{h}$ & kWh & - & - & kWh & kWh \\
\hline Variable-water-volume & $0.2 / 0.1$ & $0.2 / 0.3$ & $0.4 / 0.8$ & - & - & $4013.71 / 4022.66$ & $5.77 / 5.76$ & $7.77 / 7.76$ & $8689.75 / 8795.37$ & $88,059.84 / 85,939.04$ \\
\hline Stratified with bypass & 0.10 & 0.80 & - & 1 & 0 & 4412.52 & 5.94 & 7.10 & 6066.54 & $96,692.49$ \\
\hline Stratified without bypass & 0.20 & 0.30 & - & 1 & 2000 & 3980.48 & 5.80 & 7.87 & 8829.11 & $164,376.83$ \\
\hline $\begin{array}{c}\text { Stratified with limitation in } \\
\text { the energy recovered by } \\
\text { the system }\end{array}$ & 0.30 & 0.20 & - & 1 & 200 & 4178.97 & 5.73 & 7.50 & 7853.57 & $87,638.00$ \\
\hline $\begin{array}{l}\text { Stratified with limitation in } \\
\text { the total water use of } \\
\text { the system }\end{array}$ & $0.2 / 0.1$ & $0.3 / 0.8$ & - & 1 & $300 / 300$ & $4110.11 / 4149.91$ & $5.75 / 5.71$ & 7.63/7.55 & $8254.15 / 8645.73$ & $88,126.84 / 88,126.84$ \\
\hline
\end{tabular}


Considering that the results with unlimited availability of water from the low temperature energy source could correspond with an ULTDH application, the stratified case shows a slightly better system global efficiency. This could put the stratified case as the best option from the energetic point of view for a booster HP application with the ULTDH network. However, the energy use from the ULTDH network is $87 \%$ higher. Considering the cases in which a limitation is imposed, its function can be linked to a grey water energy recovery application since a limited daily grey water production is fixed. In this case, it can be concluded that the variable-water-volume case is a better option for a booster HP application with grey water energy recovery. In conclusion, the variable-water-volume case is the best option for a booster HP with energy recovery (ULTDH or grey water) from a low temperature heat source since it achieves the maximum system global efficiency with a much more reduced energy use from the source and lower heat pump and tank sizes.

\section{Variable-Water-Volume Storage Tank Implementation}

The variable-water-volume tank is shown as the best option to be coupled with a booster HP application in terms of cost (smaller tank size) and energy efficiency, overall in energy recovery applications. In this way, the authors intend to present a solution to implement this solution in a DHW application. Thus, Figure 14 introduces a sketch of what could be the real implementation of the proposed system.

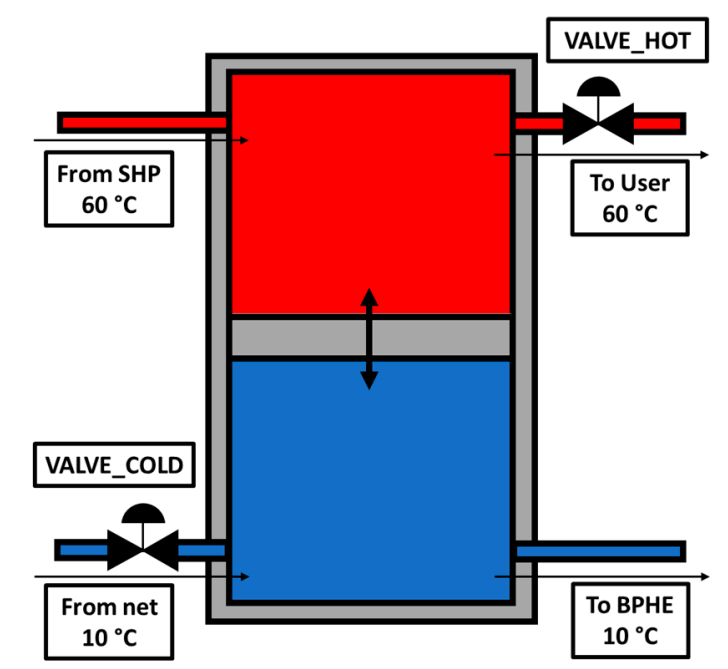

Figure 14. Sketch of the implementation of the variable-water-volume tank in a domestic hot water application.

The main problem that arises when trying to couple the variable-water-volume tank in a DHW application is related with the pressurization of it combined with the whole installation. The DHW facilities are pressurized and need the tank to be included to be also pressurized. When including the stratified option, as the volume is maintained constant, this problem is automatically solved. In order to have a similar situation for the variable-water-volume tank, the configuration shown in Figure 14 is proposed. It consists of a tank and two valves. The tank is divided in two parts by a moving wall composed of thermal isolation material in such a way that the hot water is maintained in the top part of the tank and the cold water in the bottom part. When there is a hot water demand but, according the control algorithm of the system the SHP is off, the Valve_hot is open, the hot water flows outside the tank and cold water enters inside it moving up the inner wall. When there is not hot water demand but according the control algorithm the SHP must heat water, the valve_cold is open allowing the cold water to go out the tank to the SHP and later on going inside the tank through the hot water part of the tank, in this case, the movable wall will move down. Finally, if the SHP is on and there is a demand of 
hot water, both valves will remain open. Summarizing, the Valve_cold is open when the SHP is on and the valve_hot is open when there is a demand of hot water.

\section{Conclusions}

The research work presented in this paper includes the analysis of the influence of the TES system coupled with a HP for an energy recovery application. Two alternatives of the TES system have been studied and compared: the conventional stratified storage tank and the innovative variable-water-volume storage tank. The study compares both systems from a system global energy performance perspective and to complement the conclusions an exergy analysis was also conducted.

The main results obtained show:

- Variable-water-volume tank has shown an improvement in SPFuser of 3.5\% compared to the stratified system for the same water use.

- In the stratified tank, the HRU must be used always in order to preheat the water going into the tank from the net.

- The stratified system uses less efficiently the energy input, requiring a significantly higher amount of energy input in order to be able to achieve similar SPFuser. The difference is critical in waste heat energy recovery applications where the amount of available energy is limited.

- A significantly smaller SHP-tank size from the variable-water-volume case when compared with the stratified case (half the tank size and 33\% of SHP size), which will be due to a reduced system cost. This point is a consequence of the higher exergy efficiency due to the exergy destroyed in the stratified case by the dead water volume.

- The variable-water-volume case is the best option for a booster HP with energy recovery from a low temperature heat source, ULTDH network and especially grey water network, application since it allows the system to work with the highest system global efficiency and lowest energy use from the heat source.

It is worth mentioning that in all the studies performed in the current work, as in the most of theoretical studies available in the literature, the stratification of the storage tank is not disturbed by the water ingoing or outgoing from the tank. Therefore, the penalty of using stratified tanks would be higher in real systems. In that direction, the experimental test in a pilot plant in which tank temperature is registered will supply more insight about the real losses of stratified systems and how they can be compared with variable volume ones.

Regarding the variable volume tank, this work has assumed that the system is properly designed and working during the whole year, but if the variable volume tank is oversized, some stratification phenomena could appear that must be analyzed and their impact on the storage system evaluated, but it is out of the scope of this work and this effect as well as the stratification breaking in stratified tanks will be the object of a future research.

In conclusion, the variable-water-volume case has shown to be a better option to be coupled with HP technology regarding heat recovery applications over the conventional stratified case. With a higher energy recovered rate and higher exergy efficiency that led to achieve lower SHP-sizes and simpler configuration circuit considering the same energy demand. Finally, a practical way to implement the water storage tank with the corresponding operation strategy has been proposed, showing that the idea could be implemented without increasing significantly the system cost.

Author Contributions: Conceptualization, E.N.-P. and J.M.C.; Methodology, E.N.-P.; Software, X.M.; Formal Analysis, X.M. and E.N.-P.; Investigation, X.M.; Resources, J.M.C.; Data Curation, X.M. and E.N.-P.; Writing-Original Draft Preparation, X.M.; Writing-Review \& Editing, E.N.-P. and J.M.C.; Supervision, E.N.-P. and J.M.C.; Project Administration, E.N.-P.; Funding Acquisition, E.N.-P. and J.M.C. All authors have read and agreed to the published version of the manuscript. "

Funding: "Vicerectorado de Investigación, Innovación y Transferencia of the Universitat Politecnica de Valencia (Spain)" throught the project "REDUCCIÓN DE LAS EMISIONES DE CO2 A ALTA TEMPERATURE A PARTIR 
DE LA RECUPERACION DE CALOR RESIDUAL MEDIANTE EL USO DE UNA BOMBA DE CALOR" with the reference SP20180039 from the program "Primeros proyectos de investigación (PAID-06-18)".

Acknowledgments: The authors would like also to acknowledge the Spanish 'MINISTERIO DE ECONOMIA Y COMPETITIVIDAD', throught the project. "MAXIMIZACION DE LA EFICIENCIA Y MINIMIZACION DEL IMPACTO AMBIENTAL DE BOMBAS DE CALOR PARA LA DESCARBONIZACION DE LA CALEFACCION/ACS EN LOS EDIFICIOS DE CONSUMO CASI NULO" with the reference ENE2017-83665-C2-1-P and “Vicerectorado de Investigación, Innovación y Transferencia of the Universitat Politecnica de Valencia (Spain)" throught the project "REDUCCIÓN DE LAS EMISIONES DE CO2 A ALTA TEMPERATURE A PARTIR DE LA RECUPERACION DE CALOR RESIDUAL MEDIANTE EL USO DE UNA BOMBA DE CALOR" with the reference SP20180039 from the program "Primeros proyectos de investigación (PAID-06-18)" for the given support.

Conflicts of Interest: The authors declare no conflict of interest.

\section{Appendix A}

In order to complement the results presented in this paper from the point of view of the system, the authors included an analysis of the tank. The analysis consists of an energy analysis taking the tank as control volume, and a part of the energy analysis, an exergy analysis was considered since a more perceptive basis is needed if the true usefulness of TES system is to be assessed. That is mainly due to the fact that the losses in an energy analysis only account for those that exit the boundaries of the system, but in the TES system, there are also internal exergy consumptions that the energy analysis does not consider [32]. That is why an exergy analysis was considered necessary to evaluate and compare the performance of the TES system for the SHP system. The energy and exergy analysis take as control volume the storage tank. In this manner, the facility, with the SHP and the HRU, does not take part in this analysis.

\section{Appendix A.1. Energy and Exergy Analysis Methodology}

The energy and exergy analysis of the TES system was performed based on the methodology presented in [32]. Figure A1 introduces the nomenclature scheme used for both tank configurations.

(a) Stratified storage tank model

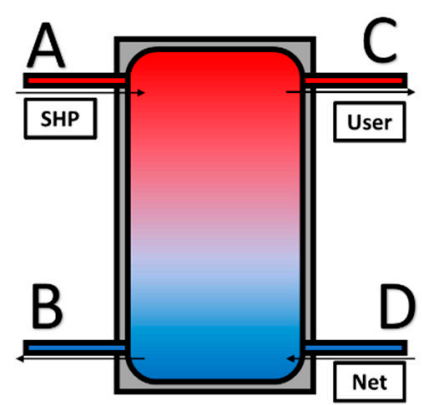

(b) Variable-water-volume storage tank model

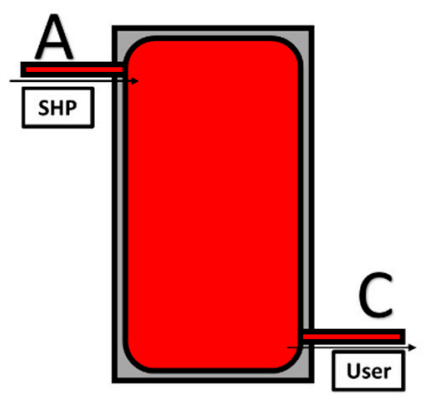

Figure A1. Nomenclature of the different tank inlets and outlets of each model. (a) Refers to the stratified model and (b) to the variable-water-volume model.

The energy balance can be written as shown in Equation (A1):

$$
E n_{\text {input }}-E n_{\text {recovered }}-E n_{\text {loss }}=E n_{\text {accumulated }}
$$

Being, En $n_{\text {input }}$ the total energy input to the tank that has been calculated as $\mathrm{H}_{\mathrm{A}}-\mathrm{H}_{\mathrm{B}}+\mathrm{H}_{\mathrm{D}}$ in the stratified case and as $\mathrm{H}_{\mathrm{A}}$ in the variable-water-volume case, $E n_{\text {recovered }}$ the energy recovered as the total energy sent to the user $\left(\mathrm{H}_{\mathrm{C}}\right), E n_{\text {loss }}$ the environmental tank losses that have been calculated using the UA method and $E n_{\text {accumulated }}$ as the energy stored in the tank. All the energy flows were calculated considering a reference temperature of the system of $10^{\circ} \mathrm{C}$, as it is the lowest temperature of the system (net temperature). 
The equation for the exergy balance can be written as shown in Equation (A2):

$$
E x_{\text {input }}-E x_{\text {recovered }}-E x_{\text {loss }}-E x_{\text {consumption }}=E x_{\text {accumulated }}
$$

Being, $E x_{\text {input }}$ the total exergy input to the tank calculated as $E x_{A}-E x_{B}+E x_{D}$ in the stratified case and as $E x_{A}$ in the variable-water-volume case, Ex recovered the exergy recovered as the total exergy sent to the user $\left(E x_{C}\right)$; $E x_{\text {loss }}$ the environmental exergy losses calculated according to Equation (A3); Ex consumption the exergy consumed in the system calculated for having balance zero in Equation (A2) and $E x_{\text {accumulated }}$ the energy stored in the tank. All the exergy flows were calculated considering a reference temperature of the system of $10^{\circ} \mathrm{C}$ :

$$
X_{l}=\sum_{\text {node }}\left(1-\frac{T_{0}}{T_{\text {node }}}\right) \cdot Q_{\text {node }}
$$

The energy and exergy efficiencies are calculated as stated in [32] and shown respectively in Equations (A4) and (A5):

$$
\begin{aligned}
& \text { Energy ef ficiency }=\frac{\text { Energy recovered }}{\text { Energy input }} \\
& \text { Exergy ef ficiency }=\frac{\text { Exergy recovered }}{\text { Exergy input }} .
\end{aligned}
$$

Appendix A.2. Energy and Exergy Analysis Results

The energy and exergy analysis have been performed considering each SHP size optimal result. Thus, in Figure A2, the results for the optimal tank volume concerning the lowest system energy consumption are presented and are the cases selected for the analysis. The results in Figure A2 show that the variable-volume case is able to reach the user energy need with lower tank volume.

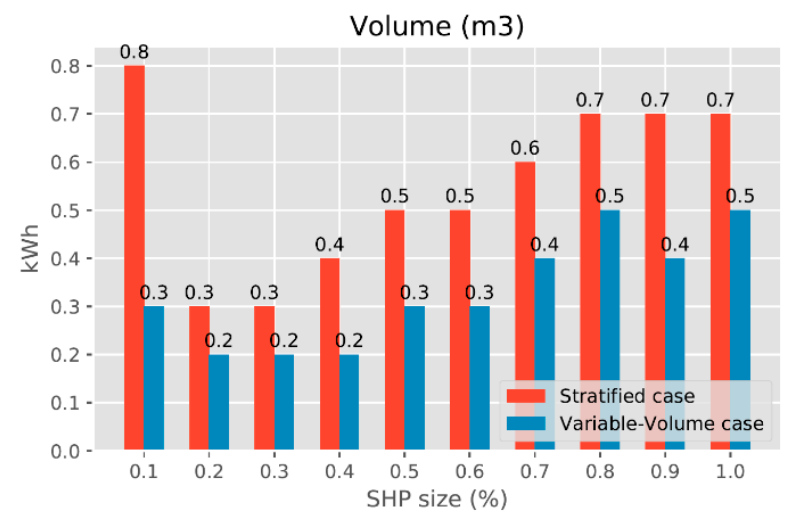

Figure A2. Optimal tank volume for the stratified and variable-water-volume case.

The results of the energy analysis are presented in Figure A3. The results show differences in the environmental losses always lower for the variable-water-volume case. This is explained since the variable-water-volume case is always able to work with a lower tank volume than the stratified case. This fact leads to a lower need of energy input and slightly higher energy efficiency than the stratified case, always considering the same user energy demand as Figure A3b shows. However, this difference on energy efficiency is only around $1 \%$. This difference, more than a better energy performance shows that the cases are able to work in a very similar condition concerning their optimal operation points. 
(a)

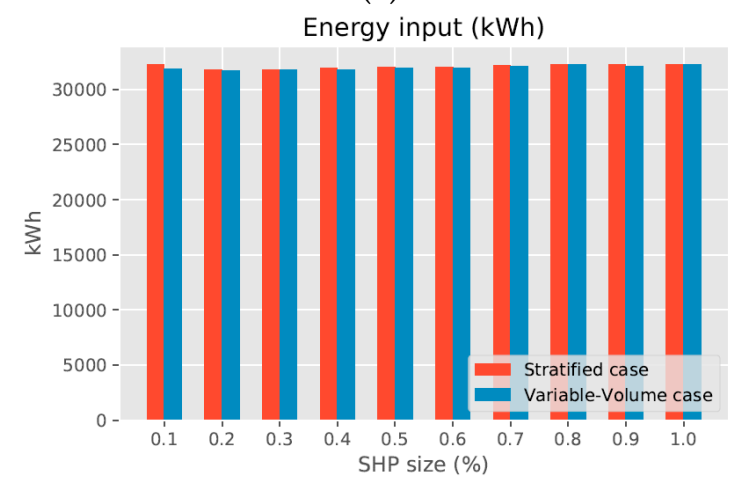

(c)

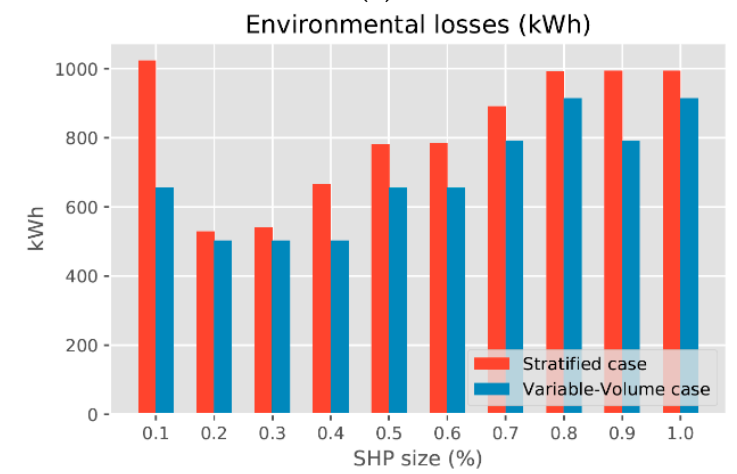

(b)

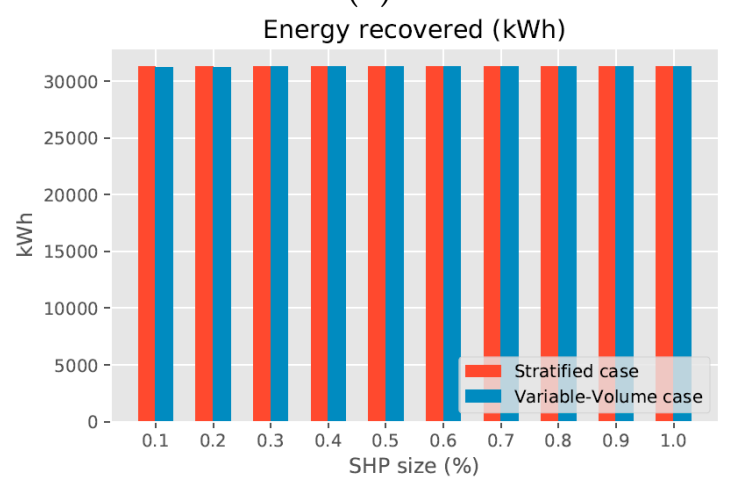

(d)

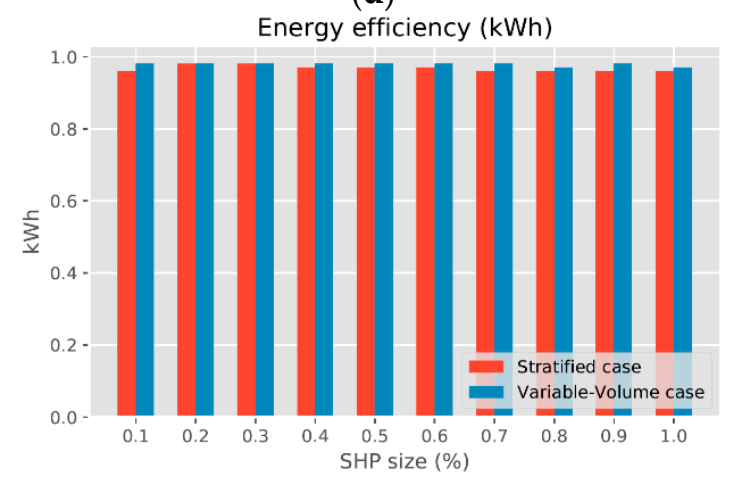

Figure A3. Results of the energy analysis: (a) Energy input to the tank, (b) Energy recovered to the mixing valve before the user, (c) Energy losses of the tank to the ambient, and (d) Energy efficiency.

The results for the exergy analysis are introduced in Figure A4. The results show much higher exergy efficiency of the variable-water-volume case over the stratified case, concretely $7.7 \%$ difference in average as Figure A4e shows. This is translated in a lower exergy input need to the tank to reach the same exergy recovered for the user. This fact is due, on one hand, to the exergy losses which similarly to the energy analysis are lower for the variable-water-volume case but with a little difference. However, the big difference is due to the exergy destroyed. The variable-water-volume case shows, see Figure A4d, no exergy destroyed at all, whereas the stratified case shows an average value of exergy destroyed of $165 \mathrm{kWh}$. This is the main difference between both cases; the higher exergy consumed by the stratified case is mainly due to the stratification of the tank. The stratified model uses the exergy input to give the user the exergy demand but also to increase the temperature of the dead water volume that due to stratification is under the set-point temperature. In contrast, the variable-water-volume model uses the exergy only to reach the user demand since there is no stratification inside the tank.

The variable-water-volume case can store more exergy per volume than the stratified. This fact is due to the stratification inside the tank. Set-point temperature is fixed at $60^{\circ} \mathrm{C}$, but only a part of the stratified tank is at set-point temperature, the rest of the tank is at lower temperature which is known as the dead water volume and thus it is not useful for the system. Part of the exergy is used for heating up the cold nodes of the tank, whereas the variable-water-volume model with all the volume at the set-point temperature uses the exergy input only for reaching the user demand. This fact allows the variable-water-volume to store more energy per volume compared with the stratified case and thus reach user comfort with lower tank volumes. 
(a)

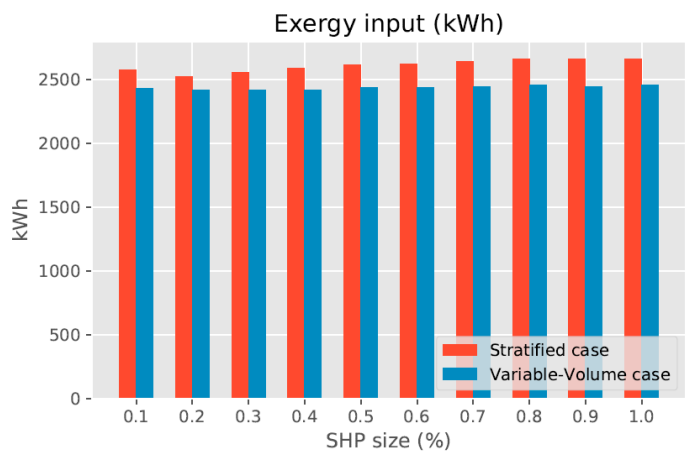

(c)

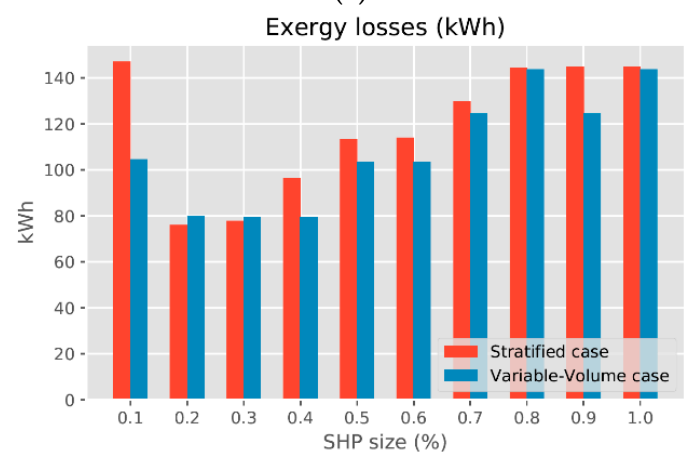

(b)

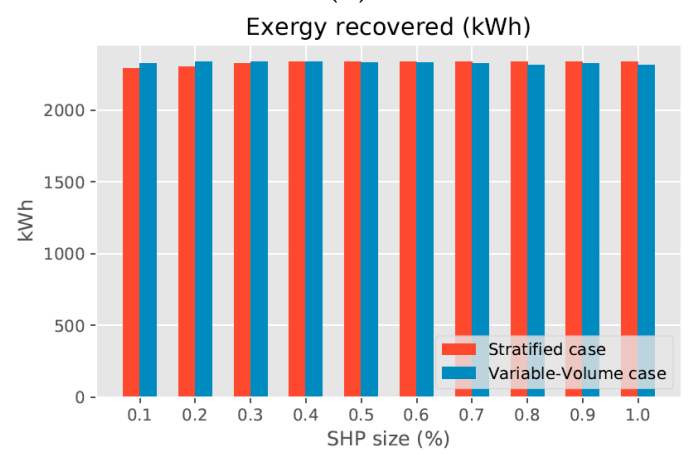

(d)

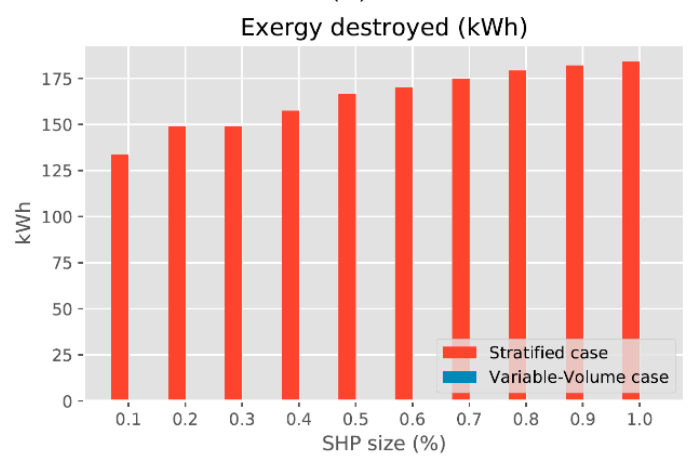

(e)

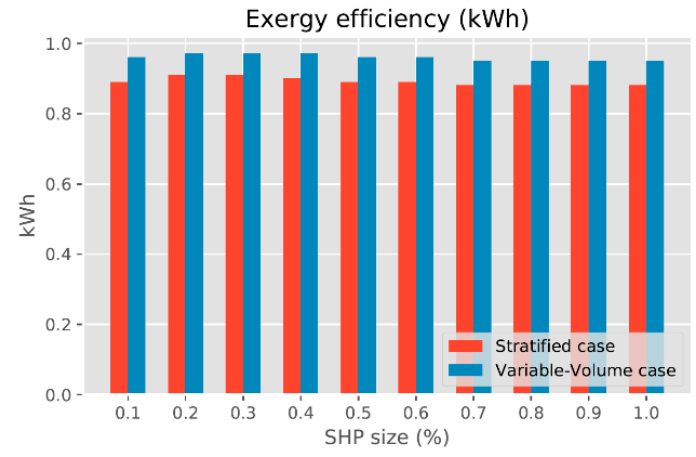

Figure A4. Results of the exergy analysis: (a) Exergy input to the tank, (b) Exergy recovered to the mxing valve before the user, (c) Exergy losses of the tank to the ambient, (d) Exergy destroyed inside the tank, and (e) Exergy efficiency.

\section{References}

1. Comssion, E. 2050 Long-Term Strategy. 2018. Available online: https://ec.europa.eu/clima/policies/strategies/ 2050_en (accessed on 12 November 2018).

2. European Comission. Energy Consumption Buildings. 2019. Available online: https:/ec.europa.eu/energy/ en/topics/energy-efficiency/buildings (accessed on 20 July 2019).

3. Comission, E. Energy Consumption in Households. 2018. Available online: http://ec.europa.eu/eurostat/ statistics-explained/index.php/Energy_consumption_in_households (accessed on 20 August 2005).

4. Directive 2008/28/EC of the European Parliament and of the Council of 11 March 2008 on the Promotion of the Use of Energy from Renewable Sources. Official Journal of the European Union. L 140/16. Available online: https://www.google.com.hk/url?sa=t\&rct=j\&q=\&esrc=s\&source=web\&cd=\&cad=rja\&uact=8\&ved= 2ahUKEwip0ubH48ztAhUEMN4KHRmLA0kQFjABegQIAxAC\&url=https\%3A\%2F\%2Feur-lex.europa. eu\%2FLexUriServ\%2FLexUriServ.do\%3Furi\%3DOJ\%3AL\%3A2009\%3A140\%3A0016\%3A0062\%3Aen\% 3APDF\&usg=AOvVaw10tSQ3SpiUkxpXKuCB6R0n (accessed on 12 November 2018). 
5. Cecchinato, L.; Corradi, M.; Fornasieri, E.; Zamboni, L. Carbon dioxide as refrigerant for tap water heat pumps: A comparison with the traditional solution. Int. J. Refrig. 2005, 28, 1250-1258. [CrossRef]

6. Pitarch, M.; Navarro-Peris, E.; Gonzálvez-Maciá, J.; Corberán, J.M. Experimental study of a subcritical heat pump booster for sanitary hot water production using a subcooler in order to enhance the efficiency of the system with a natural refrigerant (R290). Int. J. Refrig. 2017, 73, 226-234. [CrossRef]

7. Pitarch, M.; Hervas-Blasco, E.; Navarro-Peris, E.; Gonzálvez-Maciá, J.; Corberán, J.M. Evaluation of optimal subcooling in subcritical heat pump systems. Int. J. Refrig. 2017, 78, 18-31. [CrossRef]

8. Hervas-Blasco, E.; Pitarch, M.; Navarro-Peris, E.; Corberán, J.M. Study of different subcooling control strategies in order to enhance the performance of a heat pump. Int. J. Refrig. 2018, 88, 324-336. [CrossRef]

9. Nawaz, K.; Shen, B.; Elatar, A.; Baxter, V.; Abdelaziz, O. R290 (propane) and R600a (isobutane) as natural refrigerants for residential heat pump water heaters. Appl. Therm. Eng. 2017, 127, 870-883. [CrossRef]

10. Meggers, F.; Leibundgut, H. The potential of wastewater heat and exergy: Decentralized high-temperature recovery with a heat pump. Energy Build. 2011, 43, 879-886. [CrossRef]

11. Liu, L.; Fu, L.; Jiang, Y. Application of an exhaust heat recovery system for domestic hot water. Energy 2010, 35, 1476-1481. [CrossRef]

12. Chen, W.; Liang, S.; Guo, Y.; Cheng, K.; Gui, X.; Tang, D. Investigation on the thermal performance and optimization of a heat pump water heater assisted by shower waste water. Energy Build. 2013, 64, 172-181. [CrossRef]

13. Baek, N.; Shin, U.; Yoon, J. A study on the design and analysis of a heat pump heating system using wastewater as a heat source. Sol. Energy 2005, 78, 427-440. [CrossRef]

14. Mekdache, A.; Zoughaib, A.; Clodic, D. Heat Pump Driven by a Gas Engine for Heating and Domestic Hot Water Generation Heat Pump Driven by a Gas Engine for Heating and Domestic Hot Water Generation. In Proceedings of the International Conference in Refrigeration and Air Conditioning, Purdue, IN, USA, 11-17 July 2016; paper 2277.

15. Bertrand, A.; Aggoune, R.; Maréchal, F. In-building waste water heat recovery: An urban-scale method for the characterisation of water streams and the assessment of energy savings and costs. Appl. Energy 2017, 192, 110-125. [CrossRef]

16. Nehm, G.; Palandre, L.; Clodic, D.F. High Efficiency Heat Pump for Domestic Hot Water Generation. 2008. Available online: http://docs.lib.purdue.edu/iracc\%0Ahttp://docs.lib.purdue.edu/iracc/953 (accessed on 1 December 2020).

17. Thorsen, J.; Thorsen, J.E.; Markussen, W.B.; Elmegaard, B. Performance of ultra low temperature district heating systems with utility plant and booster heat pumps. Energy 2017, 137, 544-555. [CrossRef]

18. Østergaard, P.A.; Andersen, A.N. Economic feasibility of booster heat pumps in heat pump-based district heating systems. Energy 2018, 155, 921-929. [CrossRef]

19. Mugaguren, M.L.; Martínez, R.G.; Zabala, V.S.; Østergaard, K.K.; Caramaschi, M. Triple function substation and high-efficiency micro booster heat pump for Ultra Low Temperature District Heating. In IOP Conference Series: Materials Science and Engineering; IOP Publishing: Bristol, UK, 2019; Volume 609, p. 052008.

20. Østergaard, P.A.; Andersen, A.N. Booster heat pumps and central heat pumps in district heating. Appl. Energy 2016, 184, 1374-1388. [CrossRef]

21. Floss, A.; Hofmann, S. Optimized integration of storage tanks in heat pump systems and adapted control strategies. Energy Build. 2015, 100, 10-15. [CrossRef]

22. Fischer, D.; Toral, T.R.; Lindberg, K.; Wille-Haussmann, B.; Madani, H. Investigation of Thermal Storage Operation Strategies with Heat Pumps in German Multi Family Houses. Energy Procedia 2014, 58, 137-144. [CrossRef]

23. Ghaddar, N. Stratified storage tank influence on performance of solar water heating system tested in Beirut. Renew. Energy 1994, 4, 911-925. [CrossRef]

24. Han, Y.; Wang, R.; Dai, Y. Thermal stratification within the water tank. Renew. Sustain. Energy Rev. 2009, 13, 1014-1026. [CrossRef]

25. Haller, M.Y.; Haberl, R.; Mojic, I.; Frank, E. Hydraulic Integration and Control of Heat Pump and Combi-storage: Same Components, Big Differences. Energy Procedia 2014, 48, 571-580. [CrossRef]

26. Liu, F.; Zhu, W.; Cai, Y.; Groll, E.A.; Ren, J.; Lei, Y. Experimental performance study on a dual-mode $\mathrm{CO}_{2}$ heat pump system with thermal storage. Appl. Therm. Eng. 2017, 115, 393-405. [CrossRef] 
27. Khalifa, A.J.N.; Mustafa, A.T.; Khammas, F.A. Experimental study of temperature stratification in a thermal storage tank in the static mode for different aspect ratios. ARPN J. Eng. Appl. Sci. 2011, 6, 53-60.

28. Castell, A.; Medrano, M.; Solé, C.; Cabeza, L. Dimensionless numbers used to characterize stratification in water tanks for discharging at low flow rates. Renew. Energy 2010, 35, 2192-2199. [CrossRef]

29. Armstrong, P.; Ager, D.; Thompson, I.P.; McCulloch, M.D. Domestic hot water storage: Balancing thermal and sanitary performance. Energy Policy 2014, 68, 334-339. [CrossRef]

30. Rosen, M.A. The exergy of stratified thermal energy storages. Sol. Energy 2001, 71, 173-185. [CrossRef]

31. Hervás-Blasco, E.; Navarro-Peris, E.; Corberán, J.M. Optimal design and operation of a central domestic hot water heat pump system for a group of dwellings employing low temperature waste heat as a source. Energy 2019, 188, 115979. [CrossRef]

32. Dincer, M.; Ibrahim, A.R. Chapter 9. Exergy analysis of Thermal Energy Storage Systems. In EXERGY. Energy, Environment And Sustainable Development; Elsevier: Amsterdam, The Netherlands, 2007.

33. Next Generation of Heat Pumps Working with Natural Fluids (NxtHPG). Available online: http://www. nxthpg.eu/ (accessed on 7 February 2018).

34. TRNSYS. Transient Systems Simulation Homepage. Available online: http://www.trnsys.com (accessed on 1 September 2012).

35. Pitarch, M.; Navarro-Peris, E.; Gonzálvez-Maciá, J.; Corberán, J.M. Evaluation of different heat pump systems for sanitary hot water production using natural refrigerants. Appl. Energy 2017, 190, 911-919. [CrossRef]

36. Masip, X.; Cazorla-Marín, A.; Montagud-Montalvá, C.; Marchante, J.; Barceló, F.; Corberán, J. Energy and techno-economic assessment of the effect of the coupling between an air source heat pump and the storage tank for sanitary hot water production. Appl. Therm. Eng. 2019, 159, 113853. [CrossRef]

37. Cruickshank, C.A. Evaluation of a Stratified Multi-Tank Thermal Storage for Solar Heating Applications; Queen's University: Kingston, ON, Canada, 2009.

38. Newton, B.J. Modeling of Solar Storage Tanks; University of Wisconsin-Madison: Madison, WI, USA, 1995.

39. Jordan, U.; Vajen, K. DHWcalc: Program to generate Domestic Hot Water profiles with statistical means for user defined conditions. Proc. Sol. World Congr. 2005, 3, 1525-1530.

40. Spanish Norm: UNE 100030:2017. Prevención y Control de la Proliferación y Diseminación de Legionella en Instalaciones. Available online: https://www.une.org/encuentra-tu-norma/busca-tu-norma/norma?c= N0058186 (accessed on 12 November 2018).

Publisher's Note: MDPI stays neutral with regard to jurisdictional claims in published maps and institutional affiliations.

(C) 2020 by the authors. Licensee MDPI, Basel, Switzerland. This article is an open access article distributed under the terms and conditions of the Creative Commons Attribution (CC BY) license (http://creativecommons.org/licenses/by/4.0/). 